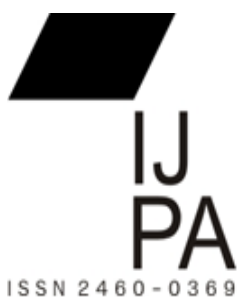

ISSN $2460-0369$

\title{
INOVASI PELAYANAN KESEHATAN 'BUMIL RISTI' SEBAGAI UPAYA MENURUNKAN ANGKA KEMATIAN IBU DAN BAYI DI PUSKESMAS SEMPU KECAMATAN SEMPU KABUPATEN BANYUWANGI

\author{
Yusticia Tria Parwita
}

\author{
Mahasiswa Administrasi Publik \\ Universitas 17 Agustus 1945 Jakarta \\ yusticiatriaparwita123@gmail.com
}

\begin{abstract}
This paper aims to describe the innovation of public services in the health sector through the Bumil Risti program at the Sempu Health Center, Sempu District, Banyuwangi Regency. Puskesmas Sempu face a problem, namely the high rate of maternal and infant mortality in Banyuwangi. The high mortality rate in this region occurs due to the slow service of pregnant women. Puskesmas Sempu create innovations in their services to be able to overcome the problems that are in the spotlight. The research findings show that the Bumil Risti service innovation carried out by Puskesmas Sempu is effective and efficient in reducing maternal and infant mortality rates in its operational areas. Innovations are made by providing services that end access, which can be obtained inside and outside the health center. By implementing this innovation, Puskesmas Sempu succeeded in eliminating the death rate in 2014 and 2015.
\end{abstract}

Keywords: Innovation, Public Service, Bumil Risti

\begin{abstract}
Abstrak Tulisan ini bertujuan untuk mendeskripsikan inovasi pelayanan publik dibidang kesehatan melalui program Bumil Risti di Puskesmas Sempu, Kecamatan Sempu, Kabupaten Banyuwangi. Puskesmas Sempu menghadapi masalah yaitu tingginya jumlah angka kematian ibu dan bayi tertinggi di Banyuwangi. Tingginya angka kematian di wilayah ini terjadi karena lambatnya pelayanan ibu hamil. Puskesmas Sempu menciptakan inovasi dalam layanan mereka untuk dapat mengatasi masalah yang menjadi sorotan. Temuan penelitian menunjukkan bahwa inovasi layanan Bumil Risti yang dilakukan oleh Puskesmas Sempu efektif dan efisien dalam menurunkan angka kematian ibu dan bayi di wilayah operasinya. Inovasi yang dilakukan dengan memberikan pelayanan yang menekankan kemudahan akses, yang dapat diperoleh di dalam dan di luar pusat kesehatan. Dengan menerapkan inovasi ini, Puskesmas Sempu berhasil meniadakan tingkat kematian pada tahun 2014 dan 2015.
\end{abstract}

Kata Kunci : Inovasi, Pelayanan Publik, Bumil Risti 


\section{PENDAHULUAN}

Pembangunan kesehatan secara menyeluruh untuk mewujudkan masyarakat yang sehat, produktif, dan berkeadilan telah diamanatkan oleh Undang-Undang Dasar 1945 pasal $28 \mathrm{H}$ ayat 1 yang menyatakan bahwa kesehatan merupakan hak asasi manusia dan investasi untuk keberhasilan pembangunan bangsa. Maka dari itu penting kiranya untuk pemerintah senantiasa melakukan pembaruan atau peningkatan pelayanan kesehatan. Peningkatan pelayanan untuk memberikan pelayanan yang lebih baik diwujudkan dengan beberapa inovasi.

Kesehatan menjadi salah satu unsur kesejahteraan suatu bangsa, serta menjadi salah satu dari tiga faktor utama yang menentukan indeks pembangunan manusia (IPM) atau Human Development Indeks (HDI). Pengertian IPM menurut BPS pusat (2016) adalah suatu indeks komposit yang mencakup tiga bidang pembangunan manusia yang dianggap sangat mendasar, yaitu usia hidup (longetivity), pengetahuan (knowledge), dan standar hidup layak (decent living). Oleh karenanya, IPM dapat diukur dari tiga indikator, yaitu (a) kesehatan masyarakat, (b) tingkat pendidikan, (c) partisipasi angkatan kerja. Pengertian tersebut menunjukkan bahwa indeks pembangunan manusia selain dapat diukur dari tingkat pendidikan dan partisipasi angkatan kerja, juga dapat diukur dari kesehatan masyarakatnya.

Kesehatan adalah salah satu faktor yang penting dan dominan dalam mendukung kelancaran setiap orang dalam beraktivitas. Reformasi di bidang kesehatan memang perlu dilakukan untuk meningkatkan pelayanan kesehatan dan menjadikannya lebih efisien, efektif serta menjangkau seluruh lapisan masyarakat berupaya mempercepat pencapaian target SDGs pada tahun 2015-2030, khususnya pada Puskesmas yang menjangkau masyarakat dan pelayanan pertama pada kesehatan masyarakat. Puskesmas Sempu mempunyai problema angka kematian ibu dan bayi yang terus meningkat. Puskesmas Sempu menjadi penyumbang terbesar angka kematian ibu dan bayi dibandingkan puskesmas lain di Kabupaten Banyuwangi. Berikut ini data angka kematian ibu dan bayi di Puskesmas Sempu tahun 2011-2015.

\section{Tabel 1.}




\section{Angka kematian ibu dan bayi di Puskesmas Sempu periode 2011-2015}

\begin{tabular}{|l|l|r|}
\hline Tahun & AKB & AKI \\
\hline 2011 & 11 & 0 \\
\hline 2012 & 11 & 4 \\
\hline 2013 & 17 & 5 \\
\hline 2014 & 0 & 0 \\
\hline 2015 & 0 & 0 \\
\hline Total & 39 & 9 \\
\hline
\end{tabular}

Berdasarkan Tabel 1 di atas, angka kematian bayi di tahun 2011 sebanyak 11 jiwa dan angka kematian ibu nol (0). Pada tahun 2012 kematian bayi sebanyak 11 jiwa dan kematian ibu sebanyak 4 jiwa. Tahun 2013 angka kematian bayi sebanyak 17 jiwa dan angka kematian ibu sebanyak 5 jiwa. Ditahun 2014 dan 2015 angka kematian bayi dan ibu zero (0). Angka kematian bayi dan ibu terlihat tinggi di tahun 2013 jika dilihat dari standar angka kematian ibu dan bayi nasional yaitu AKI 102/100.000KH dan AKB 23/1000KH. Tingginya AKB dan AKI disebabkan karena beberapa faktor diantaranya: 1) Rendahnya kesadaran masyarakat akan pentingnya pemeriksaan kehamilan secara berkala , 2) Keterlambatan penanganan yang disebabkan oleh kondisi geografis dan askes transportasi yang sulit, 3) Rendahnya kemampuan masyarakat dalam pembiayaan kehamilan dan persalinan, 4) Masih tingginya angka pernikahan dini.

Desentralisasi bidang kesehatan memberi ruang yang besar bagi pemerintah daerah untuk melakukan inovasi pelayanan kesehatan masyarakat. Kewenangan yang besar pada era desentralisasi menuntut pemerintah daerah lebih aktif membuat berbagai kebijakan publik khususnya sektor kesehatan. Kabupaten Banyuwangi telah mempunyai banyak inovasi kebijakan kesehatan yang berupaya menurunkan angka kematian ibu dan bayi, salah satunya melalui Program Ibu Hamil Resiko Tinggi (Bumil Risti) terkhusus untuk ibu hamil yang tinggal jauh dari puskesmas.

Penelitian ini menggunakan model penelitian kualitatif dan tipe penelitian fenomenologis. Metode penelitian yang digunakan oleh penulis dalam pembahasan tulisan ini yaitu metode yang dilakukan dengan studi kasus dan studi kepustakaan. Studi kasus 
yaitu menganalisis berdasarkan kasus-kasus yang ada dan yang sudah pernah terjadi. Studi kepustakaan yaitu dengan menggunakan sumber-sumber dari data primer berupa jurnal ilmiah, peraturan perundang-undangan, buku-buku, media online, artikel dan tulisan yang berhubungan dengan materi yang dituliskan Setelah data yang ada terhimpun, maka dilakukan pengolahan dan analisis terhadap data sehingga dapat menjawab pertanyaan: Bagaimana inovasi Pelayanan Kesehatan BUMIL RISTI dalam upaya untuk mengurangi Angka Kematian Ibu dan Angka Kematian Bayi di Puskesmas Sempu Kecamatan Sempu Kabupaten Banyuwangi?

\section{KAJIAN TEORITIS}

\section{Inovasi Sektor Publik}

Menurut Sumarto (2009:14), inovasi adalah upaya untuk memperkenalkan sesuatu yang baru, artinya ide baru, metode baru, dan pendekatan baru, serta upaya untuk mencari solusi kreatif dalam rangka meningkatkan partisipasi dan memperbaiki kinerja governance. Dengan adanya pengertian di atas inovasi diartikan bahwa inovasi tidak selalu dianggap sebagai perubahan yang menyimpang, tetapi lebih dianggap sebagai upaya untuk mengisi dan menyesuaikan antara keadaan wilayah setempat

Manfaat yang ingin dicapai dengan adanya inovasi dapat berupa efektivitas, kecepatan, biaya murah dan rasa senang atau bangga atas layanan yang diterima. Inovasi dalam pelayanan publik mempunyai ciri khas, yaitu bersifat intangiable artinya karena inovasi pelayanan publik dalam organisasi tidak hanya diartikan dengan munculnya suatu produk baru yang dapat dilihat, tetapi dapat dilihat dari hubungan pelakunya dalam suatu perubahan.

Tipologi inovasi sektor publik menurut Muluk (2008) yaitu, terdapat inovasi produk atau pelayanan, yang selanjutnya di dalam pelayanan terdapat proses, metode, kebijakan dan sistem pelayanan.

a. Inovasi produk atau layanan berdasarkan perubahan bentuk dan desain produk atau layanan. 
b. Inovasi proses pelayanan berasal dari adanya pembaruan kualitas yang berkelanjutan dan berkembang dengan perubahan organisasi, prosedur dan kebijakan yang dibutuhkan dalam berinovasi. Inovasi proses pelayanan dapat dibedakan menjadi dua kriteria, yaitu inovasi terusan (sustaining innovation) dan inovasi proses (discontinues innovation). Sustaining Innovation merupakan proses inovasi yang membawa perubahan baru namun dengan tetap mendasarkan diri pada kondisi pelayanan dan sistem yang sedang berjalan atau produk yang sudah ada. Discontinues Innovation merupakan proses inovasi yang membawa perubahan yang sama sekali baru dan tidak lagi berdasarkan pada kondisi yang sudah ada sebelumnya.

c. Inovasi metode pelayanan adalah cara baru berinteraksi dalam memberikan pelayanan kepada masyarakat. Metode pelayanan biasanya dapat dirasakan ketika face to face, kini dapat berkembang hanya dengan menggunakan teknologi digital.

d. Inovasi kebijakan mengacu pada visi, misi, tujuan, dan strategi yang baru.

e. Inovasi sistem adalah berkembangnya interaksi sistem yang mencakup cara baru atau cara yang diperbarui dalam berinteraksi dengan aktor-aktor lain atau dapat dikatakan perubahan dalam tata kelola pemerintahan.

\section{Pelayanan Publik}

Pelayanan Publik oleh Roth (dalam Istianto 2011:106) sebagai any service available to the public whether provided publicly (as is a museum) or privately (as is a retaurant meal). Menurut Roth, pelayanan publik merupakan suatu pelayanan yang telah disediakan jika untuk kepentingan publik disediakan oleh pemerintah. "Any service" yang dikemukakan oleh Roth berkaitan dengan barang dan jasa dalam pelayanan. Pelayanan publik yang dimaksud adalah segala bentuk kegiatan pelayanan yang dilakukan oleh suatu organisasi atau individu dalam bentuk barang dan jasa kepada masyarakat baik secara individu maupun kelompok atau organisasi.

Dengan perkembangan ilmu dan pemikiran manusia, pandangan terhadap administrasi sudah berubah dari aslinya karena dianggap tidak sesuai sehingga muncullah pengertian baru. Seperti yang dikemukakan Anastasia (2009: 5) "Di Indonesia administrasi 
diartikan sebagai fungsi dari pada atau apa yang harus dijalankan oleh setiap orang yang bertugas kewajiban memimpin atau mengepalai suatu organisasi”. Administrasi dalam perkembangannya dihadapkan pada persoalan yang semakin rumit, yang menyangkut tugas pelayanan (service) dari masyarakat yang semakin kompleks. Dalam perkembangannya, ilmu administrasi digolongkan menjadi dua golongan besar yaitu administrasi negara (publik administration) dan administrasi bisnis (busines administration) (Anastasia, 2009: $8)$.

\section{PEMBAHASAN}

\section{Inovasi Pelayanan Ibu Hamil Risiko Tinggi (Bumil Risti)}

Bumil Risti merupakan akronim dari Ibu Hamil Resiko Tinggi yang merupakan layanan jasa di bidang kesehatan secara gratis pada masyarakat dengan mengedepankan pelayanan prima dan paripurna khususnya ibu hamil dengan resiko tinggi guna menekan angka kematian ibu dan bayi di wilayah kerja Puskesmas Sempu. Merupakan gerakan menurunkan Angka Kematian Ibu (AKI) dan Angka Kematian Bayi (AKB) sejak tahun 2016. Program Bumil risti yang dicanangkan Kabupaten Banyuwangi terpilih menjadi inovasi terbaik bidang kesehatan dari Jaringan Informasi Pelayanan Publik (JIPP) Pemprov Jawa Timur.

Ide program yang sebelumnya digelorakan oleh Puskesmas Sempu itu, awalnya bertujuan untuk mempertahankan Zero kematian Ibu hamil dan anak. Kriteria Ibu hamil yang berisiko tinggi, diantaranya: a) berusia kurang dari 20 tahun dan di atas 35 tahun, b) jarak kelahiran yang terlalu dekat, c) banyak anaknya, d) persalinan pertama operasi, e) memiliki riwayat hipertensi, f) tinggi badannya kurang dari $150 \mathrm{~cm}$.

Kabupaten Banyuwangi dengan luas wilayah 5.782,50 km2 didiami penduduk sebanyak 1.668.438 jiwa, terdiri dari 838.856 jiwa laki-laki dan 829.582 jiwa perempuan, penduduk ini tersebar di 24 Kecamatan. Angka kematian bayi di Kabupaten Banyuwangi dari tahun 2010- 2014 memiliki nilai yang fluktuatif. Pada tahun 2010 sebesar 7.2 dari 1000 kelahiran hidup. Pada tahun 2011 mengalami penurunan menjadi 6.71 dari 1000 
kelahiran hidup. Namun AKB kembali naik cukup signifikan di tahun 2012 hingga mencapai angka 9.3 kematian bayi dari 1000 kelahiran hidup.

Pada tahun 2013, AKB kembali turun menjadi 8.2 kematian bayi dari 1000 kelahiran hidup. AKB kembali turun cukup signifikan yaitu 6.09 di tahun 2014 dan mengalampeningkatan kembali di tahun 2015 yakni menjadi 6.82 dari 1000 kelahiran hidup. Pada tahun 2016 AKB mengalami penurunan menjadi 5.5 kematian bayi dari 1000 kelahiran hidup, ini artinya pelaksanaan pelayanan kesehatan di kabupaten Banyuwangi memenuhi target yang telah dilaksanakan. Hal ini secara visual ditampilkan pada tabel berikut.

\section{Tabel 2.}

\section{Presentase Angka Kematian Bayi (AKB)}

Per 100000 Kelahiran Hidup

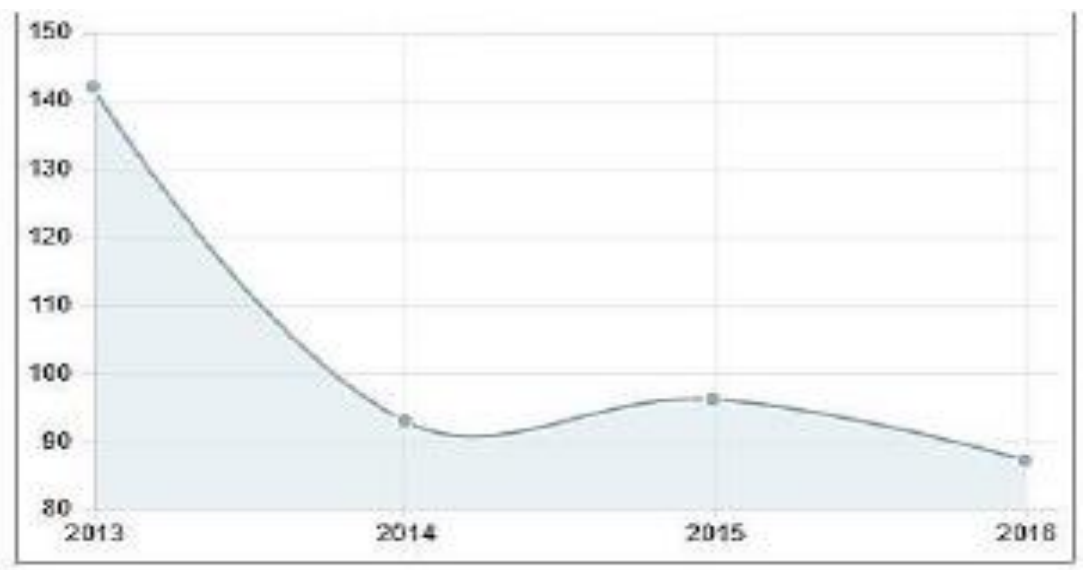

Sumber : Data Seputar Kesehatan Kabupaten Banyuwangi https://www.banyuwangikab.go.id/profil/profil-kesehatan.html

\section{Inovasi Produk/Layanan Bumil Risti}

Pada inovasi produk, puskesmas membuat produk unggulan bernama Bumil Risti yang merupakan produk layanan jasa gratis kepada ibu hamil dengan pendampingan secara eksklusif agar kehamilan lebih terkontrol. Produk Bumil Risti ini merupakan produk unggulan yang dibentuk oleh Puskesmas Sempu pada 2016 yang menjadi pembaharu produk unggulan sebelumnya yaitu SAKINA (Stop Angka Kematian Ibu dan Anak) pada akhir tahun 2013, dengan lebih meningkatkan peran serta masyarakat. 
Di dalam program Bumil Risti terdapat laskar atau tim yang bertugas mendampingi dan memantau ibu hamil resiko tinggi. Dalam upaya ini, pemerintah kabupaten Banyuwangi bekerja sama dengan tukang sayur disekitar daerah kecamatan Sempu yang telah diberikan beberapa fasilitas pendukung seperti motor dan handphone yang sudah terhubung dengan layanan kesehatan di puskesmas Sempu.

\section{Inovasi Proses Layanan Bumil Risti}

Inovasi proses layanan adalah perubahan atau pembaruan kualitas pelayanan yang terus berlanjut atau bahkan menciptakan suatu alur proses pelayanan yang baru guna mempermudah pengguna layanan. Inovasi proses layanan dalam sektor publik mencakup serangkaian peristiwa yang diambil dari masalah sekitar yang tujuannya agar dapat menyelesaikan masalah sebelumnya. Keberadaan program inovasi pelayanan Bumil Risti di Puskesmas Sempu yaitu memberikan pelayanan yang lebih eksklusif dalam menangani ibu hamil di wilayah kerja Puskesmas Sempu, baik ibu hamil tanpa resiko maupun resiko rendah, tinggi, ataupun sangat tinggi.

Proses pelayanan yang dilakukan berdasarkan prinsip pelayanan yaitu kemudahan akses. Proses pelayanan kepada ibu hamil dilakukan di dalam puskesmas dan di luar puskesmas. Inovasi proses pelayanan yang dilakukan puskesmas melalui program tersebut termasuk dalam kategoti inovasi terusan (sustaining inovation) yaitu proses inovasi yang membawa pembaruan baru namun dengan tetap mendasarkan diri pada kondisi pelayanan dan sistem yang sedang berjalan atau produk yang sudah ada sebelumnya.

Proses pelayanan sebelum program inovasi Bumil Risti ini yaitu pasien ibu hamil yang harus berperan aktif untuk memeriksakan kehamilannya dengan datang langsung ke puskesmas, sesuai dengan jadwal yang sudah diberikan oleh bidan. Ibu hamil juga harus melewati serangkaian alur pelayanan yang ada di Puskesmas Sempu. Proses pelayanan pada ibu hamil pada program inovasi pelayanan Bumil Risti tidak jauh beda dengan proses pelayanan yang lama, yaitu SAKINA. Hanya, peran masyarakat juga turut aktif dalam menyukseskan program ini, seperti pedagang sayur keliling. Karena dalam upaya menurunkan $\mathrm{AKB} \& \mathrm{AKI}$ tidak hanya peran bidan atau tenaga puskesmas yang lebih aktif 
dan responsif dalam mengawal kesehatan kehamilan ibu hamil khususnya yang beresiko tinggi dan sangat tinggi, tetapi juga peran serta masyarakat.

Proses pelayanannya yaitu Laskar Bumil Risti (pedagang sayur keliling) berkeliling desa untuk menjual dagangannya seperti hari biasa. Setelah menemukan ibu hamil, kader langsung menelpon bidan wilayah/bidan desa untuk menginformasikan sesuai dengan informasi dari ibu hamil. Ketika dalam proses pemeriksaan ditemukan keluhan yang memerlukan cek laboraturium, bidan akan segera menelpon ambulance puskesmas untuk menjemput ibu hamil dan membawanya ke Puskesmas Sempu.

Inovasi pelayanan pada ibu hamil melalui inovasi Bumil Risti dilakukan di luar dan di dalam puskesmas, ketika pelayanan dilakukan di dalam puskesmas pelaksana (tenaga medis) menggunakan SOP standar yang sudah ada dipuskesmas. Akan tetapi, jika pelayanan dilakukan di luar puskesmas pelaksana (tenaga medis) beracuan pada SOP inovasi. Inovasi proses layanan Bumil Risti ini tidak hanya dalam pemeriksaan rutin seperti yang telah dipaparkan di atas. Akan tetapi, inovasi pelayanannya juga menyangkut pada pelayanan ibu hamil resiko tinggi yang akan melahirkan. Hal ini karena tujuan dari inovasi tersebut adalah mengawal dan mendampingi ibu hamil sejak awal kehamilan, persalinan, dan pascapersalinan.

Tabel 3.

Proses Pelayanan Sebelum dan Sesudah Inovasi

\begin{tabular}{|l|l|}
\hline \multicolumn{1}{|c|}{ Sebelum } & \multicolumn{1}{c|}{ Sesudah } \\
\hline $\begin{array}{l}\text { Pasien mendaftar di loket pusk } \\
\text { esmas }\end{array}$ & $\begin{array}{l}\text { Pasien memberi informasi kebidan melalui laskar } \\
\text { Bumil Risti }\end{array}$ \\
\hline Pasien antri di ruang tunggu & Pasien menunggu di rumah \\
\hline Pasien diperiksa di poli KIA & Pasien diperiksa di rumah \\
\hline $\begin{array}{l}\text { Pasien menebus resep di apote } \\
\mathrm{k}\end{array}$ & Bidan langsung memberikan \\
obat melalui laskar Bumil Risti
\end{tabular}

Sumber: Data dioleh dari hasil penelitian

Inovasi Metode Pelayanan Bumil Risti 
Inovasi metode pelayanan adalah cara baru berinteraksi dalam memberikan pelayanan kepada masyarakat. (Yeremias, 2008) Metode pelayanan biasanya dapat dirasakan ketika berhadapan langsung atau face to face, namun dapat juga menggunakan teknologi digital. Dalam hal ini Puskesmas Sempu menggunakan metode pelayanan dengan face to face atau berhadapan langsung dengan pasien (ibu hamil) dengan metode jemput bola.

Penggunaan metode ini dirasa lebih efektif karena berhubungan langsung dengan pelayanan kesehatan. Dengan metode pelayanan yang dilakukan Puskesmas Sempu dengan metode jemput bola, pelayanan kesehatan akan dapat dirasakan secara merata, baik yang tinggal di desa strategis maupun desa terpencil. Metode pelayanan pada inovasi Bumil Risti ini menggunakan metode jemput bola, artinya bidan desa dan laskar Bumil Risti yang akan mendatangi rumah pasien (ibu hamil) untuk melakukan deteksi awal kehamilan beresiko dan pemeriksaan kehamilan secara berkala yang meliputi pemeriksaan wajib K1-K4.

Pemeriksaan kepada ibu hamil harus mencakup K1-K4. Hal tersebut penting untuk melihat perkembangan janin pada setiap tahapannya. $\mathrm{K}$ adalah singkatan dari kunjungan, yang artinya bidan akan melakukan kunjungan sebanyak empat kali dalam masa kehamilan. Kunjungan dilakukan pada setiap trimester K1 (trimester pertama), K2 (trimester kedua), K3\&K4 (trimester ketiga). (Azwar, 2010)

Metode pelayanan Bumil Risti dengan jemput bola dirasa sudah sangat baik karena bermanfaat bagi ibu hamil. Manfaatnya telah dirasakan langsung oleh ibu hamil baik yang beresiko maupun yang tidak beresiko, yang mana mereka merasa sangat terbantu dan dimudahkan dalam mendapatkan pelayanan kesehatan kehamilan. Hal ini karena sebelumnya yang menjadi kendala ibu hamil selain faktor geografis, yaitu kurangnya kepedulian suami terhadap istri yang tidak mau mengantar istrinya untuk periksa ke puskesmas dengan alasan kerja, capek, dan asumsi bahwa "periksa rutin itu tidak penting, yang penting ibunya sehat".

Berdasarkan pemaparan hasil penelitian di atas, teori Muluk tentang inovasi sektor publik yang terdiri atas lima tipologi. Namun, penulis hanya mendeskripsikan hasil penelitian dengan menggunakan tiga tipologi yaitu inovasi produk, proses layanan, dan 
metode pelayanan. Penulis tidak mendeskrpsikan tentang inovasi kebijakan dan sistem karena adanya inovasi Bumil Risti tidak mengubah standart yang sudah ada, tetapi hanya menambahkan alur/prosedur inovasi pelayanan yang dilakukan di luar puskesmas. Ketika pelayanan dilakukan di dalam puskesmas kembali menggunakan alur atau standar prosedur baku yang ada di puskesmas. Berikut ini ditampilkan ringkasan hasil penelitian sesuai dengan teori Muluk untuk mempermudah pemahaman.

\section{Tabel 4.}

Ringkasan hasil penelitian berdasarkan teori Muluk (2008)

\begin{tabular}{|l|l|}
\hline Bidang Inovasi & Bentuk Inovasi \\
\hline Inovasi Produk/ layanan & $\begin{array}{l}\text { Puskesmas Sempu membuat program inovasi yang } \\
\text { bernama Bumil Risti, yang merupakan inovasi layanan } \\
\text { jasa di bidang kesehatan secara gratis pada ibu hamil } \\
\text { dan khususnya ibu hamil dengan resiko tinggi dengan } \\
\text { pendampingan secara eksklusif agar kehamilan lebih } \\
\text { terkontrol melalui laskar Bumil Risti. }\end{array}$ \\
\hline Inovasi Proses layanan & $\begin{array}{l}\text { Pada proses pelayanan puskesmas mengedepankan } \\
\text { prinsip kemudahan akses, dimana pelayanan pada ibu } \\
\text { hamil dapat dilakukan di dalam puskesmas dan di luar } \\
\text { puskesmas yang siap melayani 24 jam. }\end{array}$ \\
\hline $\begin{array}{l}\text { Inovasi Metode Pelayan } \\
\text { an }\end{array}$ & $\begin{array}{l}\text { Dengan menerapkan metode jemput bola. Bidan dan } \\
\text { Laskar Bumil Risti yang akan mendatangi rumah ibu } \\
\text { hamil untuk melakukan pemeriksaan kehamilan rutin. }\end{array}$ \\
\hline
\end{tabular}

\section{Faktor Pendukung dan Faktor Penghambat Inovasi Pelayanan Bumil Risti}

1. Faktor Pendukung $\square$ Komitmen tim pelaksana program Dalam hal ini, tim pelaksana program akan mewujudkan keberhasilan programnya. Dengan adanya komitmen dari tim pelaksana program, masingmasing jabatan akan sadar diri dan lebih bertanggung jawab dalam pelaksanaan tugasnya. (Suwarno, 2008) $\square$ Adanya Kerjasama Kerjasama yang dilakukan dapat berupa kerjasama pada lintas sektor dan lintas program. $\square$ Sosialisasi yang berkelanjutan Kegiatan sosialisasi dilakukan 
untuk memberikan informasi terkait manfaat dan pentingnya program tersebut. Sosialisasi yang dilakukan dengan memberikan informasi berjenjang dimulai dari sosialisasi di tingkat kecamatan, desa, dan dusun.

2. Faktor Penghambat Kesadaran Masyarakat Peran masyarakat dalam program inovasi tersebut yaitu dalam kegiatan program, mereka memiliki hak sebagai pengguna jasa program dan ikut mengevaluasi jalannya program. Akan tetapi masyarakat kurang menyadari penitngnya pemeriksaan kehamilan secara rutin, sehingga mereka kadang-kadang sulit untuk digerakkan. $\square$ Kemampuan bidan wilayah Permasalahan pada kehamilan semakin hari semakin berkembang. Hal ini karena ketika ada permasalahan pada ibu hamil kadang-kadang bidan wilayah tidak dapat menangani sehingga ibu hamil harus dirujuk ke puskesmas ataupun rumah sakit daerah. Hal ini jika tidak segera diatasi, pelaksanaan inovasi pelayanan akan terhambat.

\section{SIMPULAN}

Inovasi pelayanan Bumil Risti kepada ibu hamil yang dilakukan Puskesmas Sempu merupakan pelayanan yang efektif dan efisien dalam menurunkan angka kematian ibu dan bayi yang ada di wilayah kerja Puskesmas Sempu. Hal ini dilihat dari inovasi proses layanan dan metode pelayanan yang digunakan sehingga inovasi tersebut dapat memberikan pelayanan kesehatan pada ibu hamil secara merata hingga ke pelosok-pelosok desa.

Pada inovasi proses pelayanan puskesmas lebih mengedepankan prinsip pelayanan kemudahan akses, yang pelayanan pada ibu hamil dapat dilakukan di dalam puskesmas dan di luar puskesmas. Inovasi metode pelayanan yang baru yaitu dengan jemput bola dengan melakukan pemeriksaan kehamilan dengan mendatangi rumah ibu hamil. Untuk dapat menemukan keberadaan ibu hamil secara cepat, bidan dibantu oleh yang namanya laskar Bumil Risti. Laskar tersebut berasal dari pedagang sayur keliling yang akan mencari dan menemukan keberadaan ibu hamil dengan cara menjual sayurnya berkeliling seperti biasa. Manfaat dari ditemukannya ibu hamil sejak dini yaitu dapat dipantau dan didampingi mulai awal kehamilan hingga menjelang persalinan agar kehamilannya tidak beresiko. 


\section{DAFTAR PUSTAKA}

Angraini, Mita. 2017. Inovasi Pelayanan SAKINA di Puskesmas Sempu Kecamatan Sempu Kabupaten Banyuwangi (SAKINA Service Innovation at Sempu Public Health Center, Sempu Sub-Regency, Banyuwangi Regency) . Jurnal E-SOSPOL Vol. IV Edisi 2; Mei - Agustus 2017; hal. 75 - 81

Azwar, Azrul. 2010. Pengantar Administrasi Kesehatan. Jakarta: Binarupa Aksara. banyuwangikab.go.id/profil/profil-kesehatan.html diakses 26 Januari 2018

Istianto, Bambang. 2009. Manajemen Pemerintahan Dalam Perspektif Pelayanan Publik. Jakarta:

Jatim.bps.go.id diakses tgl 26 Januari 2018

Keban, Yeremias T. 2008. Enam Dimensi Strategis Administrasi Publik (konsep, teori, dan isu). Yogyakarta: Gava Media.

Muluk, Khairul. 2008. Knowledge Management Kunci Sukses Inovasi Pemerintah Daerah. Jatim: Bayumedia Publishing.

Murdyastuti, Anastasia. 2009. Teori Administrasi Publik. Malang: Universitas Brawijaya Malang.

Sumarto, Hetifah Sj. 2009. Inovasi, Partisipasi, dan Good Governance. Jakarta: Yayasan Obor Indonesia.

Suwarno, Yogi. 2008. Inovasi Disektor Publik. Jakarta:STIA-LAN Press. 